\title{
Damage evolution of concrete under loading history and sulfate attack
}

\author{
Yanming Shao ${ }^{1, a}$, Jingzhou $\mathrm{Lu}^{1, \mathrm{~b}^{*}}$ and Lizong $\operatorname{Tian}^{1, \mathrm{c}}$ \\ ${ }^{1}$ School of Civil Engineering,Yantai University,Yantai,264005,China \\ ayanmingshao@126.com, blujingzhou@sina.com, `ytutz@163.com
}

\begin{abstract}
Keywords: concrete ;loading history ; sulfate attack ;damage ;mass change; ultrasonic velocity Abstract. The damage test of concrete with size of $100 \mathrm{~mm} * 100 \mathrm{~mm} * 300 \mathrm{~mm}$ under loading history and sulfate attack has been carried out to investigate concrete properties. Mass and ultrasonic velocity of 15 prismatic concrete which are immersed in $1 \%$ sodium-sulfate solution under different loading history are measured in the tests, respectively. Experimental results show that the mechanical properties of concrete after loading history are improved in the early stage under the effect of sulfate attack.Different loading history have a different influence on the damage process of concrete subject to sulfate attack.
\end{abstract}

\section{Introduction}

Concrete is considered a brittle material, which, for a long time ,was considered to be very durable material requiring a little or no maintenance. The assumption is largely true, except when it is subjected to highly aggressive environments. Concrete structures in fact are not only subjected to salt attack but also bearing external load. Thus, study on the damage of concrete caused by load or loading history is important. Lu et al. investigated the effect of triaxial equi-compressive loading history on the ultrasonic velocity and the relation between the strength and the ultrasonic velocity[1]. They found that the damage is in linear dependence relationship with the descent of ultrasonic velocity. It is concluded that being an important nondestructive detection method, supersonic inspection is convenient and applicable to estimation of damage of concrete during loading history in engineering practice.

It is now recognized that external load alone is not sufficient, the degree of harshness of the environmental condition to which concrete is exposed over its entire life is equally important. In the literature there are numerous published works on the deterioration of concrete caused by sulfate attack, such as, Suleiman et al. explored effect of surface treatment on durability of concrete exposed to physical sulfate attack. They found that the damage process highly depends on the pore structure of the concrete surface through which salty water rises by capillary action and that protecting the concrete surface can potentially enhance its durability to salt weathering. Yang et al. investigated the effect of sulfate and chloride attack combined with mechanical loading on the dynamic modulus of concrete specimens made with two different w/c ratios. Their experimental results showed that sulfate attack initially has a positive effect on concrete performance but this reverses with time and significant deterioration can occur in concrete suffered from a long term sulfate attack[2].There is strong evidence that sulfate attack can lead to a remarkable reduction in the load bearing capacity of concrete materials [3].

This paper presents an experimental investigation on evolution of the mass and ultrasonic velocity of concrete specimens immersed in $1 \%$ sodium-sulfate solution with and without loading history. In the remaining sections of this paper, the experimental program and results will be thoroughly discussed.

\section{Experimental program}

\section{Preparation of specimens}

Fifteen specimens were cast in the shape of a prism with dimensions of $(100 \mathrm{~mm} \times 100 \mathrm{~mm} \times 400 \mathrm{~mm})$ and three were casted in standard cubes $(150 \mathrm{~mm} \times 150 \mathrm{~mm} \times 150 \mathrm{~mm})$ used to the strength test . Ordinary Portland cement (CEMI-42.5), gravel with particle size ranging from 5 to $20 \mathrm{~mm}$, river sand with $2.7-2.8$ fineness modulus and tap water were used for making the concrete specimens. Proportions of tested concrete 
mixtures were cement $325 \mathrm{~kg}$, sand $696 \mathrm{~kg}$, aggregate $1184 \mathrm{~kg}$ and water $195 \mathrm{~kg}$ per cubic meter, of which the sand rate was $37 \%$. The w/c ratio of the tested specimens was 0.60 , which had compressive strengths corresponding to $\mathrm{C} 30$. All of the specimens were demoulded after $48 \mathrm{~h}$ and then cured in a laboratory with a relative humidity $>95 \%$ and a temperature of $17-23^{\circ} \mathrm{C}$, for 28 days.

\section{Testing methods}

The 15 prism specimens were immersed in $1 \% \mathrm{Na}_{2} \mathrm{SO}_{4}$ solution with wet-dry cycles after experiencing the following stress level of loading history shown in Table 1.All tests were carried out at a room temperature of $20^{\circ} \mathrm{C}$. Table 1 also describes the number of concrete specimens in each case and the notations used to represent the tests.

Table 1. Number of concrete specimens and corresponding marks.

\begin{tabular}{llcl}
\hline \multirow{2}{*}{ Environment } & Loading history & Specimen Number & Corresponding marks \\
\hline & without & 3 & LH0 \\
\multirow{2}{*}{$1 \% \mathrm{Na}_{2} \mathrm{SO}_{4}$ with } & $10 \%$ stress level & 3 & LH10 \\
wet-dry cycles & $25 \%$ stress level & 3 & LH25 \\
& $50 \%$ stress level & 3 & LH50 \\
& $50 \%$ stress level and cyclic loading & 3 & CLH50 \\
\hline
\end{tabular}

\section{Visual inspection}

Concrete specimens were visually monitored for less than three months of sulfate exposure in wet-dry cycles and loading history. The apparent physical performance was observed directly with the naked eye or common magnifying glass, to see the development of crack on specimen surface.

\section{Mass change}

Concrete prisms were transferred to the exposure condition after measuring their initial mass using a balance with an accuracy of $0.01 \mathrm{~kg}$. Before measuring their initial mass, all concrete prisms were airdried in the laboratory until constant mass was reached. Taking the average value of three specimens' quality as the quality of the specimen in each condition, the mass change rate was calculated according to Eq. (1):

$$
W_{m}=\frac{M_{n}-M_{0}}{M_{0}} \times 100 \%
$$

where $W_{m}$ is the rate of the mass change, $M_{0}$ is the initial mass of the prismatic specimen; $M_{n}$ is the mass of the prismatic specimen at every ten days.

\section{Ultrasonic velocity}

The damage of the concrete specimens in tests was monitored by ultrasonic techniques. The propagation speed of ultrasound in these prisms was detected by ZBL-U510 ultrasonic testing equipment every ten days, whose changes reflect the evolution of damage in concrete. For a purpose of comparison, the ultrasonic velocity was determined as well before the prisms were exposed to sulfate solution.

\section{Experimental results}

\section{Visual inspection}

Fig. 1 shows concrete prisms after 40 days and 80 days of sulfate exposure. It can be observed that damage was confined to the concrete surface without either surface scaling or substantial degradation compared to the literature [4]. But specimens start to lose corner and edge after 40 days exposure, and with time going on, things are even worse at 80 days. In regard to the effect of crack, a wider crack width was found to lead to a slightly higher rate of drying[5]. When there was a crack in the surface of concrete, water permeated more quickly through a wider crack, regardless of w/c, reaching deep into the concrete with relative ease. Sulfate ions are transported into the pores of compact area layer-by-layer, thus, the exfoliation damage is generally observed in the compact area and the two-stage erosion mechanism is still applicable[6]. It can be infered from above that concrete specimens will lose corner and edge gradually and eventually deteriorate its performance after a long term sulfate exposure. 


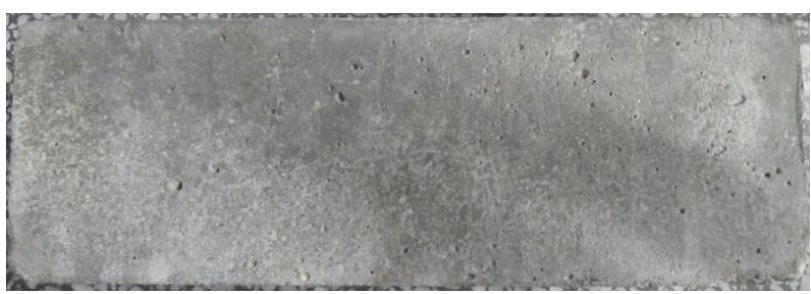

(a)

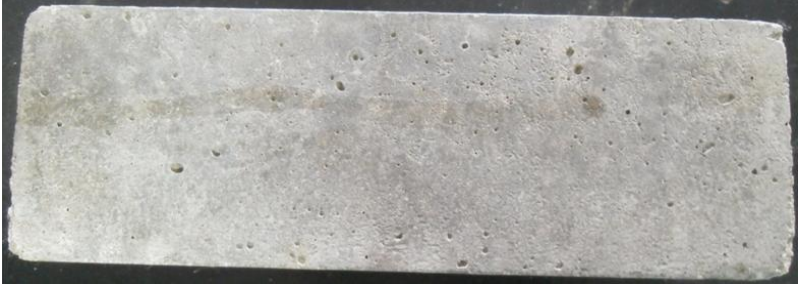

(b)

Fig.1.Concrete prisms under sulfate attack: (a) after 40 days ;(b) after 80 days .

\section{Mass change}

The mass change of concrete specimens totally immersed in the $1 \%$ sodium sulfate solution with wet-dry cycles under different loading history was monitored on a ten-day basis. Fig. 2 illustrates the evolution of mass change for different loading-history concrete prisms after nearly three months of exposure to physical sulfate attack. At early days, all the concrete prisms gained mass due to water evaporation and salt crystallization. At later age, concrete prisms start to lose mass. The highest mass change occurs for concrete prisms under $25 \%$ stress level of loading history, followed by the prisms under $50 \%$ stress level of cyclic loading history. This demonstrates that $25 \%$ monotone loading history or $50 \%$ cyclic loading history can accelerate the sulfate diffusion in concrete. While it is observed from Fig. 2, that, the mass change for concrete specimen under $10 \%$ or $50 \%$ stress level of loading history is lower than that under no loading history, which explains sulfate diffusion in concrete pore is not facilitated under the load history of $10 \%$ and $50 \%$ stress level.

\section{Ultrasonic velocity}

Fig. 3 shows the evolution of ultrasonic velocity of the specimens immersed in $1 \% \mathrm{Na}_{2} \mathrm{SO}_{4}$ solution with different loading history. It is interesting to note from Fig. 3 that the ultrasonic velocity of all specimens increased initially with immersion time, which fully indicates that sulfate attack has a positive effect on the damage of concrete in the early days. It is probably due to the continuous hydration of the cement which results in reduced porosity and improved mechanical properties. When the specimen immersed in sulfate solution with wet-dry cycles is also subjected to a $10 \%$ or $25 \%$ stress level of loading history, its ultrasonic velocity does not vary greatly compared with that subjected to no loading history. It's likely because that the $10 \%$ or $25 \%$ stress level of loading history applied is not big enough to have a significant effect on the material properties. It also can be seen fromFig. 3 that for specimens immersed in $\mathrm{Na}_{2} \mathrm{SO}_{4}$ solution subjected to $50 \%$ stress level of both monotone and cyclic loading history the ultrasonic velocity initially increased but then decreased quickly after the maximum, especially under cyclic loading. This indicates that the existence of loading history with higher stress level can accelerate the sulfate accumulation in concrete and the damage process of concrete subject to sulfate attack.
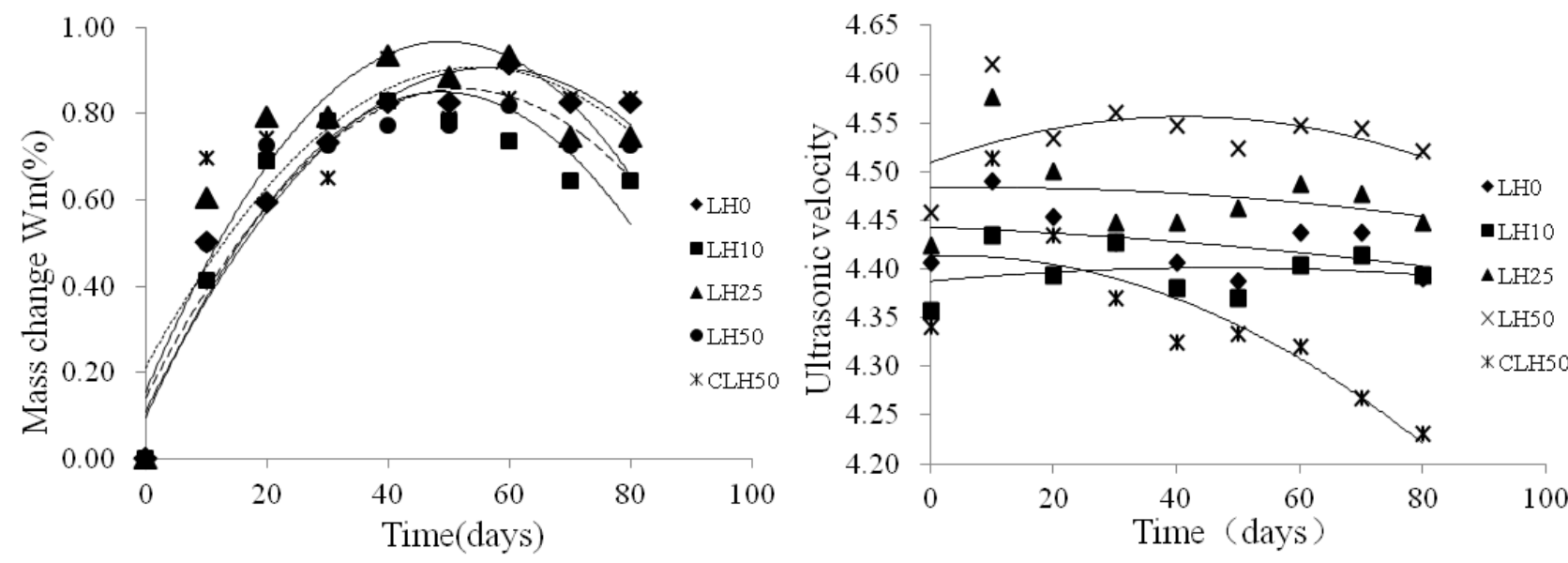

Fig.2. $\mathrm{W}_{\mathrm{m}}$ under $\mathrm{Na}_{2} \mathrm{SO}_{4}$ solution and loading history

Fig.3. Ultrasonic velocity under $\mathrm{Na}_{2} \mathrm{SO}_{4}$ and loading history 


\section{Conclusions}

This paper has presented an experimental investigation on evolution of the mass and ultrasonic velocity of concrete specimens immersed in solutions of different sodium-sulfate concentrations with and without loading history. From the experimentally obtained results, the following conclusions can be drawn:

(1) Concrete properties are degraded under the combined effects of sulfate attack and loading history. It can be infered that concrete specimens will lose corner and edge gradually and eventually deteriorate its performance after a long term sulfate exposure.

(2) Concrete prisms under monotone loading history with $25 \%$ stress level or cyclic loading history with $50 \%$ stress level have the higher mass change. While concrete prisms under monotone load history of $10 \%$ or $50 \%$ stress level have a lower mass change than that without loading history.

(3) Sulfate attack has a positive effect on the damage of concrete in the early days. And the $10 \%$ or $25 \%$ stress level of loading history applied is not big enough to have a significant effect on the ultrasonic velocity of concrete. The existence of loading history with higher stress level can accelerate the sulfate accumulation in concrete and the damage process of concrete subject to sulfate attack.

\section{Acknowledgements}

This work was financially supported by the National Natural Science Foundation of China (\#51479174) and the Shandong Nature Science Foundation (ZR2012EEM014), which are gratefully appreciated.

\section{References}

[1] Jingzhou Lu, Gao Lin, Zhe Wang and Shiyun Xiao, Supersonic Inspection for Concrete Due To Triaxial Equi-compressive Loading History „J. Journal of Basic Science and Engineering, 2005, 13(3): 313-319.(In Chinese)

[2] Ding-yi Yang, Jing-jing Luo. The damage of concrete under flexural loading and salt solution,J.Construction and Building Materials,2012,36:129-134.

[3] MH Zhang, Mq Jiang, JK Chen, Evolution of flexural strength of cement mortar attacked by sulphate ions,J.Eng Fract Mech,2008,75:4948-57.

[4] A.R. Suleiman, A.M. Soliman, M.L. Nehdi, Effect of surface treatment on durability of concrete exposed to physical sulfate attack ,J. Construction and Building Materials,2014,73:674-681.

[5] Dong-Woo Ryu, Jeong-Won Ko, Takafumi Noguchi, Effects of simulated environmental conditions on the relative humidity and relative moisture content distribution of exposed concrete,J.Cement \& Concrete Composites, 2011,33:142-153.

[6] Di-tao Niu, You-de Wang, Rui Ma, Jia-bin Wang, Shan-hua Xu, Experiment study on the failure mechanism of dry-mix shotcrete under the combined actions of sulfate attack and drying-wetting cycles, J. Construction and Building Materials,2015,81:74-80. 